\title{
Asymptomatic Malaria and Associated Risk Factors among School Children in Sanja Town, Northwest Ethiopia
}

\author{
Ligabaw Worku, ${ }^{1}$ Demekech Damtie, ${ }^{1}$ Mengistu Endris, ${ }^{1}$ \\ Sisay Getie, ${ }^{1}$ and Mulugeta Aemero ${ }^{2}$ \\ ${ }^{1}$ School of Biomedical and Laboratory Sciences, University of Gondar, P.O. Box 196, Gondar, Ethiopia \\ ${ }^{2}$ Department of Biology, University of Gondar, P.O. Box 196, Gondar, Ethiopia
}

Correspondence should be addressed to Ligabaw Worku; ligabaw@gmail.com

Received 18 March 2014; Revised 30 June 2014; Accepted 1 July 2014; Published 17 September 2014

Academic Editor: Stephen Munga

Copyright (C) 2014 Ligabaw Worku et al. This is an open access article distributed under the Creative Commons Attribution License, which permits unrestricted use, distribution, and reproduction in any medium, provided the original work is properly cited.

Introduction. Asymptomatic malaria is prevalent in highly endemic areas of Africa and is new challenge for malaria prevention and control strategies. Objective. To determine the prevalence of asymptomatic malaria and associated risk factors among school children in Sanja Town, northwest Ethiopia. Methods. A cross-sectional study was conducted from February to March 2013, on 385 school children selected using stratified proportionate systematic sampling technique. Pretested questionnaire was used to collect sociodemographic data and associated risk factors. Giemsa-stained thin and thick blood films were examined for detection, identification, and quantification of malaria parasites. Data were entered and analyzed using SPSS 20.0 statistical software. Multivariate logistic regression was done for assessing associated risk factors and proportions for categorical variables were compared using chi-square test. $P$ values less than 0.05 were taken as statistically significant. Results. The prevalence of asymptomatic malaria was $6.8 \%(n=26)$. The majority of parasitemic study participants had low parasite density $65.5 \%(17 / 26)$. Level of grade, age, bed net usage, and frequent exposure to malaria infection were associated with risk of asymptomatic malaria. Conclusion. Asymptomatic malaria was low in this study area and is associated with level of grade, age, bed net usage, and frequent exposure to malaria infection.

\section{Background}

Malaria is one of the most widespread human parasitic diseases ranking first in terms of its socioeconomic and public health importance in tropical and subtropical region of the world, especially in sub-Saharan African and Southeast Asian countries [1-4].

Various estimates have been made to measure the global burden of malaria. In 2010, the World Health Organization estimates more than 216 million cases of malaria and 655.000 deaths occur every year worldwide, with 106 countries at risk of malaria infection, among which $91 \%$ of deaths occurred in sub-Saharan Africa, 6\% in Southeast Asia, and 3\% in Eastern Mediterranean Region [1, 5, 6].

Malaria is also major public health problem and obstacle to socioeconomic development in Ethiopia [7]. About $75 \%$ of the geographic area of the country has malaria transmission (defined as areas $<2,000 \mathrm{~m}$ ), with $68 \%$ (i.e.,
54.2 million) of the country's total population living in these areas [8]. According to the Federal Ministry of Health (FMOH) 2009/2010 report, malaria accounts for up to $14 \%$ of outpatient consultations (the leading cause of outpatient consultations) and $9 \%$ of health facility admissions, with 510 million clinical malaria cases each year. However, of these, only one million are reported at the national level, with 462,623 (55.84\%) examined and 256,487 (23.68\%) confirmed positive by a diagnostic test. According to FMOH reports, approximately 70,000 people die of malaria each year in Ethiopia [9].

The major clinical features of malaria include severe anemia, cerebral malaria, hypoxia, and placental infection during pregnancy [10]. Whereas severe headache, fever, vomiting, anemia, and loss of appetite are the clinical features of uncomplicated malaria; among these, severe anemia and cerebral malaria constitute the major cause of death [11]. In addition, continuous exposures to Plasmodium parasites 
lead to the development of partial immunity for protection against further complication and, consequently, the creation of asymptomatic carrier [12]. Asymptomatic cases provide a fundamental reservoir of parasites and they might become gametocyte carriers, contributing to the persistence of malaria transmission [13]. Also, there are reports that parasites from asymptomatic carrier are more infectious than symptomatic one [14].

Most of the studies of malaria depend on clinical manifestations, severity, and complication because it is the principal cause of malaria-related deaths. Researchers and clinicians have established diagnostic criteria based on the clinical manifestations upon disease onset, which have aided in forming an integrated approach to improving the management and treatment of severe malaria [15].

Diagnosing asymptomatic malaria is not straightforward due to the obvious lack of clinical manifestations and often low level of parasites [16]. Asymptomatic malaria is prevalent in malaria endemic regions and has become a serious cause for concern as efforts are increasing towards eliminating the parasite [17]. Particularly, subpatent malaria is still transmissible and will complicate elimination of malaria in high transmission regions.

In Ethiopia, the current malaria control methods largely focus on early detection of parasite on suspected individual and treatment, insecticide-treated bed nets (ITN) and indoor residual spraying. Since individuals with asymptomatic parasitaemia will not be identified by early detection and treatment programs, they may continue to serve as a source of infection for vector mosquitoes, complicating control measures [14].

Asymptomatic malaria is a new challenge for national strategic plan for malaria prevention and control (2011-2015): a situation in which a human Plasmodium reservoir is maintained, with individuals who are not treated because they are not diagnosed, since they are asymptomatic. On the other hand, the diagnosing of such cases becomes difficult because of the low level of parasitemia; therefore, the present study was aimed at determining the magnitude of asymptomatic malaria and associated risk factors among school children of Sanja General Elementary School in Sanja Town, northwest Ethiopia.

\section{Methods}

2.1. Study Design. A cross-sectional study was conducted from February 1 to March 30, 2013, at Sanja General Elementary School children aged 6 to 15 years in Sanja Town, northwest Ethiopia.

2.2. Study Area and Study Population. The study was carried out in Sanja General Elementary School. The town Sanja is located $792 \mathrm{~km}$ far from the capital city Addis Ababa on the roadside to Gondar-Humera. Sanja has an altitude of $1800 \mathrm{~m}$ above sea level, with annual rainfall range from 800 to $1800 \mathrm{~mm}$ and annual temperature range from $25^{\circ} \mathrm{C}$ to $42^{\circ} \mathrm{C}$. There are two elementary, one junior, and one high school. One health center gives service for the dwellers of the town and the surrounding areas. There is a river known as Sanja that flows throughout the year. Sanja General Elementary School is located on the west of the main road. A total of 2079 (872 male, 1207 female) students were enrolled in the school for 2012/13 academic years. Those students, enrolled in the school during the study period, were used as study population.

2.3. Sampling and Sample Size Determination. The sample size was determined using statistical formula $\left(n=\left(z^{2} p(1-\right.\right.$ $\left.p) d^{2}\right)$ ) considering $95 \%$ confidence interval and $50 \%$ prevalence. Based on this assumption 385 study participants were selected from 2079 students. To select the study subjects, the students were first stratified according to their educational level (Grade 1 to Grade 8). Allocation of student was proportional to the number of students in each grade. Finally, the study subjects were selected using systematic sampling by using class roster as the sampling frame. Every fifth study subject was selected for the study.

\section{Data Collection}

3.1. Sociodemography and Risk Factors Assessments. Well structured questionnaire based on the known risk factors for asymptomatic malaria was locally developed specifically in English version by the research team. It was later translated into the Amharic, local language of the study area. Comparisons were made on the consistency of the two versions. The questionnaires address students' sociodemographic information and risk factors around. A pretest was conducted and any ambiguous questions and repetitive ideas were corrected. Additional response categories were also added based on the pretest findings.

3.2. Detection, Identification, and Quantification of Malaria. It was done according to a well accepted reference (such as Cheesbrough M (200) parasitological tests in district laboratory practice in tropical countries, part 2) [18].

\section{Operational Definition}

4.1. Asymptomatic Malaria. A person with no recent history of symptoms and/or signs of malaria who shows laboratory confirmation of parasitemia [19].

4.2. Quality Control. To ensure good and reliable result, the following care was taken. Quality control of microscopy involves ensuring that good-quality Giemsa stain is used and staining procedures adhere to recognized methods. In addition, ten percent of the total slide was randomly selected and reexamined at the end by experienced laboratory technologist, who is blind to the first examination result. Double entry of data was done to maintain quality of the data, and before starting analysis, data was checked for completeness and being filled out clearly.

4.3. Data Analysis and Interpretation. Data were entered and analyzed using SPSS 20.0 (SPSS Inc., Chicago, 2011) software. Descriptive statistics was used to give a clear picture of 
TABLE 1: Prevalence of asymptomatic malaria by sex among school children.

\begin{tabular}{lccccc}
\hline \multirow{2}{*}{ Parasite } & \multicolumn{5}{c}{ Number (\%) infected } \\
& $N=132$ & $N=253$ & $N=385$ & $P$ value & $\chi^{2}$ \\
\hline P. falciparum & $10(7.6)^{*}$ & $10(54)$ & $20(5.2)$ & 0.128 & 2.31 \\
P. vivax & $3(2.3)$ & $3(1.2)$ & $6(1.6)$ & 0.414 & 0.67 \\
Total & $\mathbf{1 3 ( 9 . 8 )}$ & $\mathbf{1 3 ( 5 . 1 )}$ & $\mathbf{2 6 ( 6 . 8 )}$ & $\mathbf{0 . 0 8 0}$ & $\mathbf{3 . 0 6}$ \\
\hline
\end{tabular}

${ }^{*}$ Figures in parentheses indicate percentages.

background variables. The frequency distribution of both dependent and independent variables was worked out. Multivariate logistic regression was done for assessing associated risk factors and proportions for categorical variables were compared using chi-square test. $P$ values less than 0.05 were taken as statistically significant.

4.4. Ethical Consideration. Ethical clearance was obtained from research and ethics review committee of School of Biomedical and Laboratory Sciences, University of Gondar. Before starting the actual data collection, permission was obtained from school director. Additionally, after explaining the importance of the study, an informed written consent was obtained from study participant's parent/guardian. An assent was also taken from individual school children. Those students who were positive for malaria infection were treated according to the national protocol.

\section{Results}

5.1. Sociodemographic Characteristics. A total of 385 individuals were included in the study. Their mean age was 12.7 years (range 6 to 15 years) with standard deviation of 2.3. Among these, 132/385 (34.3\%) were males and the rest 253/385 (65.7\%) were females. Of the total 385 school children, 312 (81\%) were in the age range of $11-15$ years (Tables 1 and 2).

5.2. Prevalence of Asymptomatic Malaria. Out of the total school children, 26 (6.8\%) were positive for Plasmodium species and two Plasmodium species, P. falciparum and $P$. vivax, were identified with the prevalence of $20 / 385$ $(5.2 \%)$ and $6 / 385(1.6 \%)$, respectively. Of the 385 school children, 13/132 (9.8\%) and 13/253 (5.1\%) of males and females had asymptomatic malaria, respectively. The distribution of asymptomatic malaria among each age group showed that $11 / 73 \%(15.1 \%)$ of $6-10$ years and $15 / 312(4.8 \%)$ of the $11-15$ years were infected. Age significantly associated with both $P$. falciparum and P. vivax (Tables 1 and 2).

Regarding the level of parasitemia with respect to age and sex, $17 / 26(65.4 \%)$ had less than 500 parasites/ $\mu \mathrm{L}$; there was a significant difference in the level of parasitemia among age groups $\left(\chi^{2}=10.1, P=0.006\right)$, but there was no significant difference between the sexes (Table 3 ).

5.3. Risk Factors of Asymptomatic Malaria. Risk factors assessment in general showed that level of grade, age, bed
TABLE 2: Prevalence of asymptomatic malaria by age groups among school children.

\begin{tabular}{lccccc}
\hline \multicolumn{5}{c}{ Number (\%) infected } \\
Infection & $6-10 \mathrm{yrs}$ & $11-15 \mathrm{yrs}$ & Total & $P$ value & $\chi^{2}$ \\
& $N=73$ & $N=312$ & $N=385$ & & \\
\hline P. falciparum & $8(11)^{*}$ & $12(3.8)$ & $20(5.2)$ & 0.014 & 6.08 \\
P. vivax & $3(4.1)$ & $3(1.0)$ & $6(1.6)$ & 0.051 & 3.82 \\
Total & $\mathbf{1 1 ( 1 5 . 1 )}$ & $\mathbf{1 5 ( 4 . 8 )}$ & $\mathbf{2 6 ( 6 . 8 )}$ & $\mathbf{0 . 0 0 2}$ & $\mathbf{9 . 8 9}$ \\
\hline
\end{tabular}

${ }^{*}$ Figures in parentheses indicate percentages.

TABLE 3: Levels of parasitemia by sex and age group among the parasitemic school children.

\begin{tabular}{ccccccc}
\hline \multirow{2}{*}{ Parameter } & \multicolumn{6}{c}{ Parasite density distribution per microliter of blood } \\
& $<5000$ & $500-999$ & $\geq 1,000$ & Total & $P$ value & $\chi^{2}$ \\
\hline Sex & & & & & & \\
Male & $7(26.9)^{*}$ & $5(19.2)$ & $0(0.0)$ & $12(46.2)$ & & \\
Female & $10(38.5)$ & $2(7.7)$ & $2(7.7)$ & $14(53.8)$ & 0.16 & 3.68 \\
Total & $\mathbf{1 7 ( 6 5 . 4 )}$ & $\mathbf{7 ( 2 6 . 9 )}$ & $\mathbf{2 ( 7 . 7 )}$ & $\mathbf{2 6 ( 1 0 0 )}$ & & \\
Age/years & & & & & & \\
6-10 & $11(42.3)$ & $0(0.0)$ & $0(0.0)$ & $11(42.3)$ & & \\
$11-15$ & $6(23.1)$ & $7(26.9)$ & $2(7.7)$ & $15(57.7)$ & 0.006 & 10.1 \\
Total & $\mathbf{1 7 ( 6 5 . 4 )}$ & $\mathbf{7 ( 2 6 . 9 )}$ & $\mathbf{2 ( 7 . 7 )}$ & $\mathbf{2 6 ( 1 0 0 )}$ & & \\
\hline
\end{tabular}

${ }^{*}$ Figures in parentheses indicate percentages.

net usage, and frequent exposure to malaria infection were associated with risk of asymptomatic malaria. Students who did not have a habit of frequently used bed net were 2.1 times $(\mathrm{AOR}=2.1,95 \% \mathrm{CI}: 1.20,3.60)$ more likely to develop asymptomatic malaria. Similarly there was significant difference between exposure rates to malaria infection; more exposed group was 2.12 times $(\mathrm{AOR}=2.12,95 \% \mathrm{CI}$ : $1.06,4.40)$ more likely to have asymptomatic malaria than those who were less exposed. Age and grade significantly associated with asymptomatic malaria with the risk of 1.3 times higher in lower aged and graded groups, while sex, residence, mother/guardian education status, years of stay in the study area and surroundings, previous illness of malaria, and treatment for symptomatic malaria were not associated with asymptomatic malaria $(P>0.05)($ Table 4$)$.

\section{Discussion}

Malaria in areas of unstable transmission usually follows seasonal patterns of transmission as mosquito populations fluctuate, with the prevalence of parasitaemia at a minimum in the cooler dry season. In this time asymptomatic infections of malaria are critical, as this reservoir is likely responsible for sustaining the parasite population from one transmission season to the next [20]. Besides, asymptomatic malaria cases are difficult due to low parasitic density and availabilities of simple diagnostic methods; asymptomatic carriers especially adults are common in endemic areas and, as potential gametocyte carriers, represent an important reservoir for malaria transmission [21]. Many of these individuals can carry microscopically detectable levels of Plasmodium asymptomatically 
TABLE 4: Multivariate analysis of factors potentially associated with asymptomatic malaria infection among school children.

\begin{tabular}{|c|c|c|c|c|c|c|}
\hline \multirow{2}{*}{ Risk factors } & \multicolumn{2}{|c|}{ Malaria } & \multirow{2}{*}{ Total } & \multicolumn{2}{|c|}{ OR (95\%CI) } & \multirow{2}{*}{$P$ value } \\
\hline & Positive & Negative & & COR & AOR & \\
\hline \multicolumn{7}{|l|}{ Sex } \\
\hline Male & $13(9.8)^{*}$ & $119(90.2)$ & $132(34.3)$ & $2.02(0.85,4.80)$ & $0.966(0.344,2.713)$ & \multirow{2}{*}{0.125} \\
\hline Female & $13(5.1)$ & $240(94.9)$ & $253(65.7)$ & 1.00 & 1.00 & \\
\hline \multicolumn{7}{|l|}{ Age (years) } \\
\hline $6-10$ & $11(15.1)$ & $62(84.9)$ & $73(19)$ & $3.51(1.43,8.59)$ & $1.255(1.049,1.331)$ & \multirow{2}{*}{0.015} \\
\hline $11-15$ & $15(4.8)$ & $297(95.2)$ & $312(81)$ & 1.00 & 1.00 & \\
\hline \multicolumn{7}{|l|}{ Resident } \\
\hline Urban & $19(6.6)$ & $269(93.4)$ & $288(74.8)$ & 1.00 & 1.00 & \multirow{2}{*}{0.840} \\
\hline Rural & $7(7.2)$ & $90(92.8)$ & $97(25.2)$ & $1.10(0.41,2.89)$ & $1.278(0.428,3.830)$ & \\
\hline \multicolumn{7}{|l|}{ Grade } \\
\hline One-four & $17(13.8)$ & $111(86.2)$ & $128(33.2)$ & $4.22(1.71,10.60)$ & $1.285(1.007,1.053)$ & \multirow{2}{*}{0.040} \\
\hline Five-eight & $9(3.5)$ & $248(96.5)$ & $257(66.8)$ & 1.00 & 1.00 & \\
\hline \multicolumn{7}{|c|}{ Mothers/guardian educational status } \\
\hline Illiterate & $5(3.5)$ & $139(96.5)$ & $144(37.4)$ & $0.02(0.08,1.04)$ & $3.767(0.933,15.206)$ & \multirow{3}{*}{1.107} \\
\hline Reading and writing/1 year & $13(7.7)$ & $159(92.3)$ & $172(44.6)$ & $0.66(0.24,1.85)$ & $1.452(0.460,4.581)$ & \\
\hline 2 years at school and above & $8(11)$ & $65(89)$ & $73(19.0)$ & 1.00 & 1.00 & \\
\hline \multicolumn{7}{|l|}{ Family size } \\
\hline$\leq 4$ & $10(9)$ & $101(91)$ & $111(28.8)$ & 1.00 & 1.00 & \multirow{3}{*}{0.562} \\
\hline $5-7$ & $12(5.6)$ & $203(94.4)$ & $215(55.8)$ & $0.60(0.60,1.55)$ & $2.304(0.776,6.843)$ & \\
\hline$\geq 8$ & $4(6.8)$ & $55(93.2)$ & $59(15.4)$ & $0.73(0.18,2.71)$ & $3.138(0.630,15.588)$ & \\
\hline \multicolumn{7}{|l|}{ Years of stay } \\
\hline$<5$ years & $3(4.5)$ & $66(95.5)$ & $69(17.9)$ & 1.00 & 1.00 & \multirow{3}{*}{0.218} \\
\hline $5-10$ years & $10(10.4)$ & $84(89.6)$ & $94(24.4)$ & $2.54(0.61,12.18)$ & $1.018(0.178,5.832)$ & \\
\hline$>10$ years & $13(5.9)$ & $209(94.1)$ & $222(57.7)$ & $1.33(0.34,6.06)$ & $1.144(0.240,5.177)$ & \\
\hline \multicolumn{7}{|l|}{ Swampy area } \\
\hline Present & $2(3.7)$ & $52(96.3)$ & $54(14.0)$ & $0.49(0.08,2.24)$ & $1.189(0.212,6.004)$ & \multirow{2}{*}{0.339} \\
\hline Absent & $24(7.3)$ & 307 (92.7) & $331(86.0)$ & 1.00 & & \\
\hline \multicolumn{7}{|l|}{ Bed net usage } \\
\hline Always & $2(1.7)$ & $115(98.3)$ & $117(30.4)$ & 1.00 & 1.00 & \multirow{2}{*}{0.011} \\
\hline Sometimes/not at all & $24(9)$ & $244(91.0)$ & $268(69.6)$ & $5.66(1.27,35.23)$ & $2.111(1.200,3.604)$ & \\
\hline \multicolumn{7}{|l|}{ Ever sick by malaria before } \\
\hline Yes & $23(8.0)$ & $264(92.0)$ & $284(73.7)$ & $2.97(0.76,11.82)$ & $0.156(0.002,1.574)$ & \multirow{2}{*}{0.150} \\
\hline No & $3(3.1)$ & $95(96.9)$ & $101(26.3)$ & 100 & 1.00 & \\
\hline Frequency of illness & & & & & & \\
\hline$<5$ malaria episodes & $15(4.5)$ & $321(95.5)$ & $336(87.3)$ & 1.00 & 1.00 & 0.001 \\
\hline$>5$ malaria episodes & $9(14.9)$ & $40(85.1)$ & $49(12.7)$ & $4.82(1.81,12.67)$ & $3.185(1.063,7.064)$ & 0.001 \\
\hline Treated for symptomatic malar & & & & & & \\
\hline Yes & $23(7.8)^{\diamond}$ & $243(92.2)$ & $266(69.1)$ & 1.00 & 1.00 & 0.076 \\
\hline No & $3(3.3)^{\diamond}$ & $107(96.7)$ & $110(30.9)$ & $3.38(0.94,14.44)$ & $5.132(0.596,44.165)$ & 0.070 \\
\hline Total & $26(6.8)$ & $359(93.2)$ & $385(100)$ & & & \\
\hline
\end{tabular}

${ }^{*}$ Figures in parentheses indicate percentages.

${ }^{\diamond}$ Only for previous malaria episode.

and submicroscopic asymptomatic infections below the limit for microscopic detection that can only be detected using molecular techniques [13].

High prevalence of asymptomatic Plasmodium infection was observed $26 / 385(6.8 \%)$ in this geographical setting; this might be the effect of climate change on highland malaria transmission which is strongly dependent on the temperature, because temperature is known to influence transmission intensity through its effects on the population growth of the mosquito vector and on pathogen development within the vector [22]. This finding is very low compared to a study conducted on school children in Southwest Cameroon, which reported a prevalence of $44.3 \%$, in Yemen $12.8 \%$, in Mount Cameroon region 87.8\%, in Osogbo (Nigeria) 
25.6\%, and in Tanzania 14\% [23-27]. The reasons behind this fact remain to be clarified, but we can speculate that this might be associated with biological variability, such as genetic susceptibility related to the presence of sickle cell trait, beta-thalassaemia, or Duffy blood factor $[28,29]$ and differences in exposure to mosquito bites which are related to the living standard of the community, burden of mosquito vector, type of occupational activity, housing characteristics (e.g., screening, roof materials, and open eaves) [29, 30], and the use of selected preventative measures [31]. In addition, the biology of vector and parasites play an important role in malaria transmission to the extent that it can increase human exposure and limit the selection of control interventionsfor example, an outdoor biting pattern limits the use of IRS and bed nets [32]. The diagnostic method/design we used also differs from others.

Among malaria positive study subjects, the prevalence of P. falciparum was $76.9 \%$; this is almost similar to conducted in Indonesia $80.2 \%$ [33] and but lower than Yemen 96.7\% [26]. However, it is very high compared to a study in Southwest Cameroon $17.5 \%$ [23] and Kenya 2.9\% [29]. On the other hand, the prevalence of $P$. vivax in this study was $23.1 \%$, which is more or less comparable to $19.8 \%$ prevalence reported in Indonesia [23]. The sex distribution of asymptomatic malaria in this study showed that $9.8 \%$ were males and $5.1 \%$ were females. It is very low compared with study conducted in Cameroon, which reported that the prevalence of males was $48.1 \%$ and that of females was $41.4 \%$ [23]. This prevalence and gender difference might be due to sampled in different season and socioeconomic level that are supported with earlier access to prevention and treatment and presence or absence of mosquito breeding site throughout a year.

Regarding the level of parasitemia, result from this study showed that the majority of parasitemic study participants had low parasite density. This may be due to the low diagnostic sensitivity of routine microscopic examination. The level of parasitemia has significant association with older aged group; this might be due to repeated exposure of malaria infection.

In this study, we had also evaluated the risk factor associated with asymptomatic malaria. An association was observed between asymptomatic malaria and the age of the children where the prevalence decreased from $15.1 \%$ among children aged 6-10 years to $4.8 \%$ among children aged $11-$ 15 years $(P<0.05)$. Similar result was also reported in native Amazonian populations [34]. This may be because of increased consciousness about the transmission and information on the prevention mechanism of infection. In addition, the intensity of parasite decreases as the level of school grade increases. The results from this study demonstrated that bed net usage frequency and repeated episodes for malaria infection were strongly associated with asymptomatic malaria $(P<0.05)$. This finding is comparable with the study done in Burkina Faso [13].

\section{Conclusion}

Six point eight percent of the school children had asymptomatic malaria. Level of grade, age, bed net usage, and frequent exposure to malaria infection were associated with risk factors identified in this study. Therefore, this indicated that there is a need of further evaluation of the burden of asymptomatic malaria using more sensitive method (PCR) considering different age groups and malaria transmission level to scale up the elimination and eradication program of malaria in the country [32].

\section{Conflict of Interests}

All authors declare that they have no conflict of interests in relation to their work.

\section{Authors' Contribution}

Ligabaw Worku conceived the study, undertook statistical analysis, and drafted the initial and final paper. Mulugeta Aemero, Demekech Damtie, and Mengistu Endris initiated the study, made major contributions to the study design, reviewed the initial and final drafts of paper, and conducted data analysis. Sisay Getie participated in sample collection and the performance of laboratory diagnosis. All authors contributed to the writing of the paper and approved the submitted version of the paper.

\section{Acknowledgments}

The authors would like to thank the University of Gondar for financial support and the Department of Medical Parasitology for providing excellent laboratory facilities for processing the stool samples. They also gratefully thank the staff members of Sanja Health Center for treating the infected school children and Sanja General Elementary School staff members for supporting field work. Lastly, their thanks go to all the parents/guardians for their consent and the children who participated in this study.

\section{References}

[1] World Health Organization, World Malaria Report 2011, World Health Organization, Geneva, Switzerland, 2010.

[2] N. Minakawa, E. Omukunda, G. Zhou, A. Githeko, and G. Yan, "Malaria vector productivity in relation to the highland environment in Kenya," American Journal of Tropical Medicine and Hygiene, vol. 75, no. 3, pp. 448-453, 2006.

[3] WHO, Malaria and HIV Interactions and Their Implications for Public Health Policy, Geneva, Switzerland, 2004.

[4] S. Hochman and K. Kim, "The impact of HIV and Malaria coinfection: what is known and suggested venues for further study," Interdisciplinary Perspectives on Infectious Diseases, vol. 2009, Article ID 617954, 8 pages, 2009.

[5] World Health Organization, World Malaria Report 2010, WHO, Geneva, Switzerland, 2010.

[6] J. M. Ramos, F. Reyes, and A. Tesfamariam, "Change in epidemiology of malaria infections in a rural area in Ethiopia," Journal of Travel Medicine, vol. 12, no. 3, pp. 155-156, 2005.

[7] A. Adugna, Malaria in Ethiopia, lesson 14, http://www.ethiodemographyandhealth.org/MalariaEthiopiaAynalemAdugna.pdf. 
[8] President's malaria initiative Ethiopia. Malaria operation plan FY, 2013.

[9] C. L. MacKintosh, J. G. Beeson, and K. Marsh, "Clinical features and pathogenesis of severe malaria," Trends in Parasitology, vol. 20, no. 12, pp. 597-603, 2004.

[10] L. Malaguarnera, S. Pignatelli, J. Simporè, M. Malaguarnera, and S. Musumeco, "Plasma levels of interleukin-12 (IL12), interleukin-18 (IL-18) and transforming growth factor beta (TGF-beta) in Plasmodium falciparum malaria," European Cytokine Network, vol. 13, no. 4, pp. 425-430, 2002.

[11] T. Staalsoe and L. Hviid, "The role of variant-specific immunity in asymptomatic malaria infections. Maintaining a fine balance," Parasitology Today, vol. 14, no. 5, pp. 177-178, 1998.

[12] J. T. Bousema, L. C. Gouagna, C. J. Drakeley et al., "Plasmodium falciparum gametocyte carriage in asymptomatic children in western Kenya," Malaria Journal, vol. 3, article 18, 2004.

[13] F. P. Alves, L. H. S. Gil, M. T. Marrelli, P. E. M. Ribolla, E. P. Camargo, and L. H. P. da Silva, "Asymptomatic carriers of Plasmodium spp. as infection source for malaria vector mosquitoes in the Brazilian Amazon," Journal of Medical Entomology, vol. 42, no. 5, pp. 777-779, 2005.

[14] D. D. Laishram, P. L. Sutton, N. Nanda et al., “The complexities of malaria disease manifestations with a focus on asymptomatic malaria," Malaria Journal, vol. 11, article 29, 2012.

[15] E. Bottius, A. Guanzirolli, J. Trape, C. Regier, L. Konate, and P. Druilhe, "Malaria: even more chronic in nature than previously thought; Evidence for subpatent parasitaemia detectable by the polymerase chain reaction," Transactions of the Royal Society of Tropical Medicine and Hygiene, vol. 90, no. 1, pp. 15-19, 1996.

[16] J. F. Trape, A. Zoulani, and M. C. Quinet, "Assessment of the incidence and prevalence of clinical malaria in semi-immune children exposed to intense and perennial transmission," American Journal of Epidemiology, vol. 126, no. 2, pp. 193-201, 1987.

[17] National Five-Year Strategic Plan for Malaria Prevention and Control in Ethiopia 2006-2010, Federal Democratic Republic of Ethiopia Ministry of Health, Addis Ababa, Ethiopia, April 2006.

[18] M. Cheesbrough, Parasitological tests in district laboratory practice in tropical countrieserpart 2, Cambridge Low-pri ce editions, Cambridge University Press, 2000.

[19] Tadavis, 2010, http://www.chd11.doh.gov.ph/resu/index.php? option=com_content\&task=view\&id=27\&Itemid $=44$.

[20] A. Kamanga, P. Moono, G. Stresman, S. Mharakurwa, and C. Shiff, "Rural health centres, communities and malaria case detection in Zambia using mobile telephones: a means to detect potential reservoirs of infection in unstable transmission conditions," Malaria Journal, vol. 9, no. 1, article 96, 2010.

[21] A. L. Ouédraogo, T. Bousema, P. Schneider et al., "Substantial contribution of submicroscopical Plasmodium falciparum gametocyte carriage to the infectious reservoir in an area of seasonal transmission," PLoS ONE, vol. 4, no. 12, Article ID e8410, 2009.

[22] A. S. Sira, M. Santos-Vega, M. J. Bouma, D. Yadeta, D. Ruiz Carrascal, and M. Pascual, "Altitudinal changes in malaria incidences in highlands of Ethiopia and Colombia," Science, vol. 343, no. 6175, pp. 1154-1158, 2014.

[23] K. Helen, C. Frederick, N. Hervé et al., "An update of asymptomatic falciparum malaria in School Children, in Muea, Southwest Cameroon," Journal of Bacteriology \& Parasitology, vol. 3, p. 8, 2012.

[24] M. A. Bin Mohanna, A. S. Bin Ghouth, and Y. A. Rajaa, "Malaria signs and infection rate among asymptomatic schoolchildren in
Hajr Valley, Yemen," Eastern Mediterranean Health Journal, vol. 13, no. 1, pp. 35-40, 2007.

[25] H. K. Kimbi, E. Lum, S. Wanji et al., "Co-infections of malaria and soil-transmitted helminths in localities with different levels of urbanisation in the mount cameroon region," Onderstepoort Journal of Veterinary Research, vol. 79, no. 2, 1 page, 2012.

[26] O. Ojurongbe, A. M. Adegbayi, O. S. Bolaji, A. A. Akindele, O. A. Adefioye, and O. A. Adeyeba, "Asymptomatic falciparum malaria and intestinal helminths co-infection among school children in Osogbo, Nigeria," Journal of Research in Medical Sciences, vol. 16, no. 5, pp. 680-686, 2011.

[27] H. D. Mazigo, B. R. Kidenya, E. E. Ambrose, M. Zinga, and R. Waihenya, "Association of intestinal helminths and P. falciparum infections in co-infected school children in Northwest Tanzania," Tanzania Journal of Health Research, vol. 12, no. 4, pp. 301-308, 2010.

[28] M. C. Castro, "Environmental management of anopheles breeding sites in Dar es Salaam. Phase 1: inventory of drains in selected areas of Dar es Salaam. Final report," JICA/IMCP/UMCP/HSPH, 2007.

[29] J. Keiser, B. H. Singer, and J. Utzinger, "Reducing the burden of malaria in different eco-epidemiological settings with environmental management: a systematic review," The Lancet Infectious Diseases, vol. 5, no. 11, pp. 695-708, 2005.

[30] F. Konradsen, P. Amerasinghe, W. van der Hoek, F. Amerasinghe, D. Perera, and M. Piyaratne, "Strong association between house characteristics and malaria vectors in Sri Lanka," The American Journal of Tropical Medicine and Hygiene, vol. 68, no. 2, pp. 177-181, 2003.

[31] Y. Yé, M. Hoshen, V. Louis, S. Séraphin, I. Traoré, and R. Sauerborn, "Housing conditions and Plasmodium falciparum infection: protective effect of iron-sheet roofed houses," Malaria Journal, vol. 5, article 8, 2006.

[32] J. G. Breman, "The ears of the hippopotamus: Manifestations, determinants, and estimates of the malaria burden," American Journal of Tropical Medicine and Hygiene, vol. 64, no. 1-2, pp. $1-11,2001$.

[33] F. P. Alves, R. R. Durlacher, M. J. Menezes, H. Krieger, L. H. Pereira da Silva, and E. P. Camargo, "High prevalence of asymptomatic Plasmodium vivax and Plasmodium falciparum infections in native Amazonian populations," American Journal of Tropical Medicine and Hygiene, vol. 66, no. 6, pp. 641-648, 2002.

[34] M. Baragatti, F. Fournet, M. Henry et al., "Social and environmental malaria risk factors in urban areas of Ouagadougou, Burkina Faso," Malaria Journal, vol. 8, no. 1, article 13, pp. 1-14, 2009. 

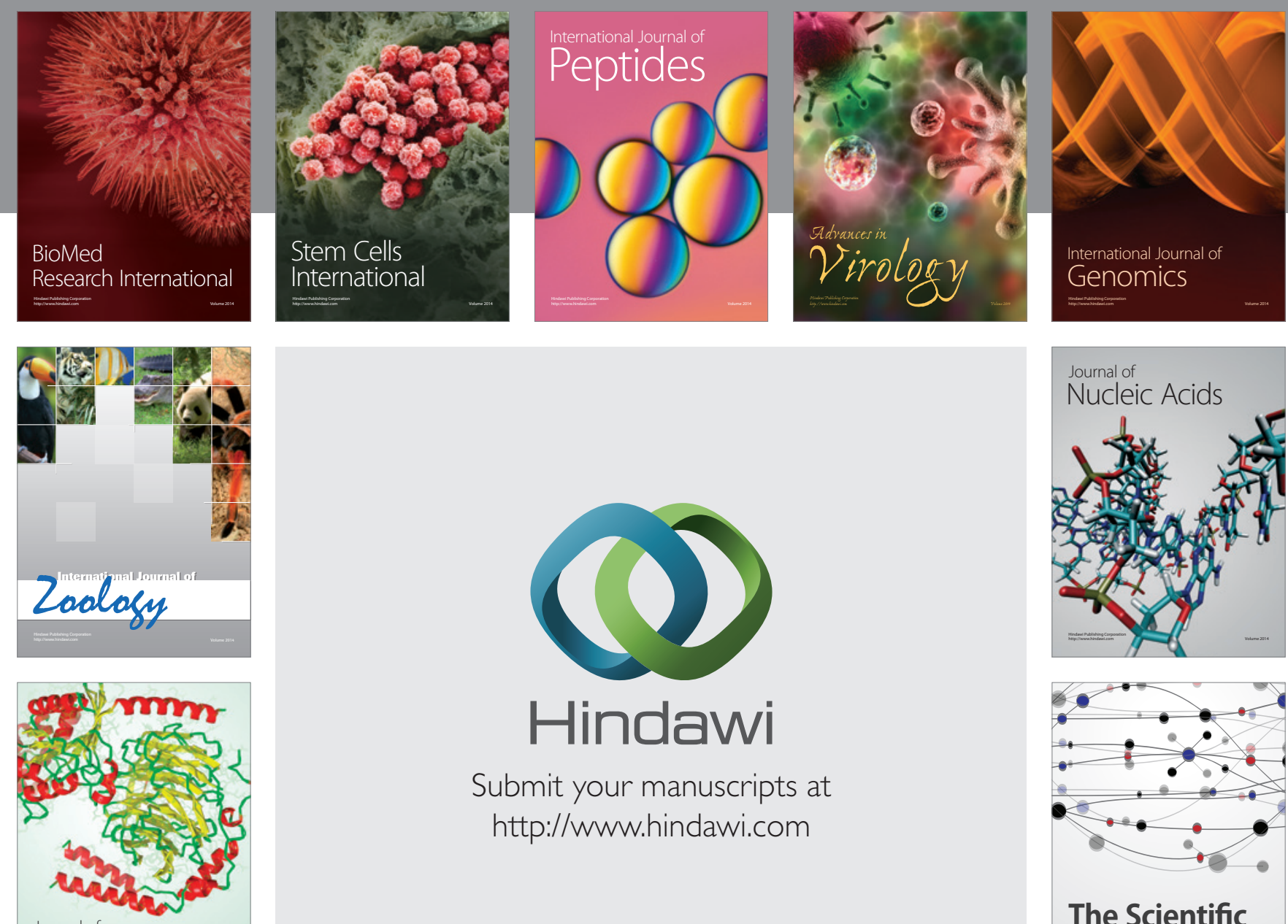

Submit your manuscripts at

http://www.hindawi.com

Journal of
Signal Transduction
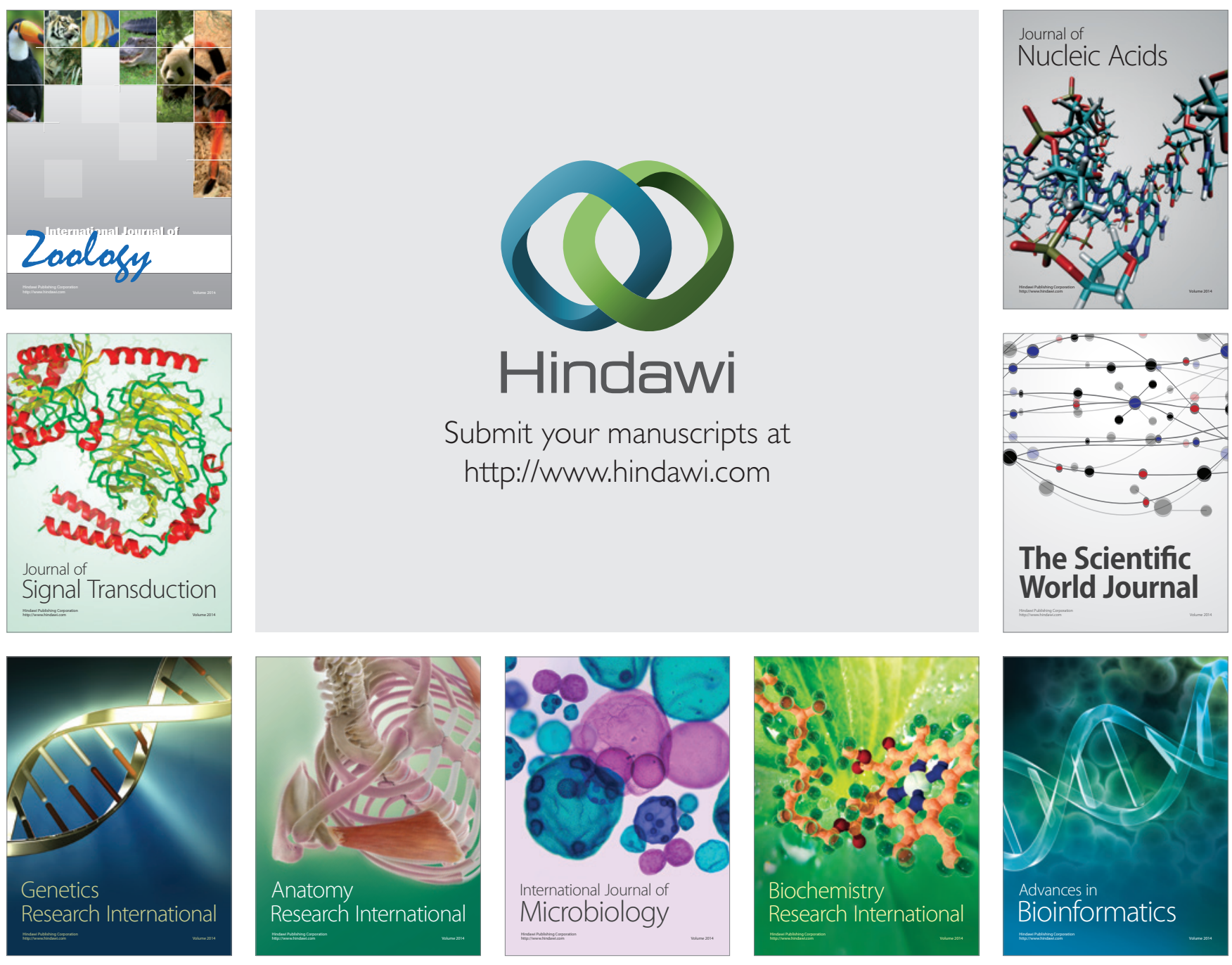

The Scientific World Journal
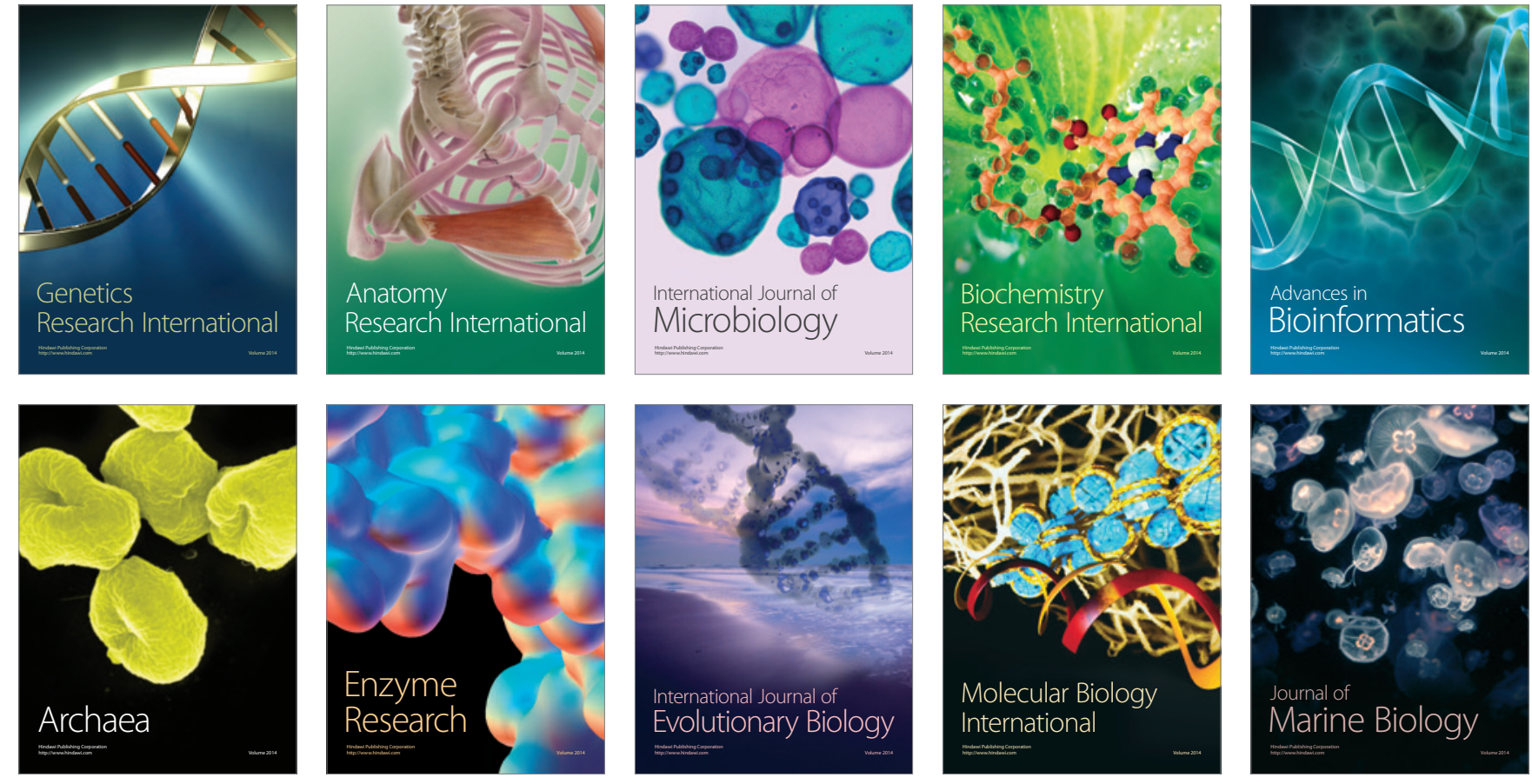